\title{
Recent Development Trend of Blockchain Technologies: A Patent Analysis
}

\author{
Yann-Jy Yang \\ Chihlee University of Technology, Taiwan \\ yjyang@mail.chihlee.edu.tw \\ Jiann-Chyau Hwang \\ MetaEdge corporation \\ joe.hwang@metaedge.com.tw
}

\begin{abstract}
Blockchain is essential for cryptocurrencies, but its use is not limited to cryptocurrency. Blockchain can be used in a wide range of applications. Recently, many blockchain inventions and applications have been proposed, which have received considerable attention from academics, industry practitioners, and the government. However, few studies have analyzed the development of blockchain technology. In this study, a patent analysis of the U.S. patents of blockchain was conducted. With an analysis of 335 patents awarded, a profile of recent blockchain technology development was obtained. The results indicated that three-quarters of the U.S. blockchain patents were originated in the United States. Half of the awarded U.S. patents are from foreign origin, and the proportion of the blockchain patent originated in the United States is more extensive, which revealed that the United States is a leader in the blockchain technology. Furthermore, 14\% of blockchain patents were awarded to IBM, indicating that IBM as a technology giant in the blockchain technology. Additionally, word cloud and $\mathrm{N}$-gram were used to reveal the relevant terms and phrases used in the abstracts of blockchain patents.
\end{abstract}

Keywords: Blockchain, Cryptocurrency, Patent Analysis, Word Cloud, N-Gram.

\section{INTRODUCTION}

With the recent development of cryptocurrencies that started from the launch of Bitcoins proposed by Nakamoto [1], cryptocurrencies have continually received considerable attention from investors, entrepreneurs, regulators, and the general public [2]. Numerous cryptocurrencies, including Bitcoins ${ }^{1}$, Bitcoin Cash $^{2}$, and Ethereum ${ }^{3}$, use decentralized control architecture without a centralized authority. In the world,

\footnotetext{
${ }^{1}$ https://en.wikipedia.org/wiki/Bitcoin

2 https://en.wikipedia.org/wiki/Bitcoin_Cash

${ }^{3}$ https://ethereum.org/
} 
there are more than five thousand cryptocurrencies with a total market capitalization of more than US\$ 255 billion and more than three hundred cryptocurrencies with a market capitalization more than US\$ ten million as of $2020^{4}$.

The design of most modern cryptocurrencies is highly based on the blockchain, which is a growing list of records called blocks or ledgers. Each block links to previous and subsequent blocks. All blocks contain a cryptographic hash of their previous blocks, timestamp, and transaction data. Blockchain is a transaction ledger because it is used to record transaction data. Decentralization is a critical advantage of blockchain that can be used to establish disintermediary peer-to-peer (P2P) transactions without mutual trust and centralized control among transaction parties [3].

The applications of blockchain are not limited to its use as the fundamental technology for cryptocurrencies. Blockchain can revolutionize industry and commerce transactions because of its abilities of immutable, transparent, secured, fast, and trustworthy functions. As an essential cryptocurrency component, blockchain is a distributed ledger that records transaction data in a verifiable and permanent approach [4]. After understanding the cryptocurrency principle, people realize that blockchain is essential for cryptocurrencies and exhibits potential for a wide range of applications, which has received increasing attention worldwide.

Blockchain can be employed for any purpose of transaction data recording. Previous studies have reported blockchain applications in various fields, such as egovernment [5], food supply information security [6, 7], energy systems [8, 9], sharing economy [10], health care [11, 12], education [13], online education [14], intellectual property management [15], banking [16], personal identity [12, 17], asset ownership $[12,18]$, supply chains $[12,19]$, and the prevention of unethical business transaction [12].

Both academics and industry practitioners have paid attention to the wide range of applications of blockchain; however, the development of blockchain technology has not been thoroughly studied. The blockchain studies have mostly focused on technology issues and industry applications of blockchain. However, if the innovative applications of blockchain are not established on patent protected technology, the applications can easily be imitated. If a blockchain application is not based on any patented technology or technology secret, the first mover firm of the innovative application can only obtain a few competitive advantages because the second mover can easily launch a similar application.

Patents and business secrets are two approaches to preventing competitors from imitating innovations. However, most blockchain applications are designed for transaction purposes. Blockchain applications must be transparent to obtain the trust of transaction parties; thus, maintaining business secrets is not easy because everything should be transparent. Therefore, applying patents is a more suitable strategy than maintaining secrets to secure competitive advantages obtained from blockchain innovations.

According to the aforementioned discussion, this study focused on the development trend of blockchain technologies that are essential for decentralized online transactions. In this study, a bibliometric analysis of blockchain technology was performed using patent data. To the best of our knowledge, currently, a complete profile of granted blockchain patents by time, by countries, and by applicants (companies) is

\footnotetext{
4 According to coinmarketcap.com, as of January 30, 2020, there were 5,076 cryptocurrencies exchanged in 20,325 transaction markets. The total market capitalization was US\$255 billion.
} 
unavailable. Thus, an overview of granted patents was provided to reveal the current development of blockchain technology.

\section{PATENT DATA COLLECTION AND ANALYSIS}

A patent data analysis was considered an essential approach to evaluate innovation [20], monitor the development trends of technologies [21-23], and forecast technologies $[24,25]$. Studies have employed the patent analysis to explore the technology development of countries [26] and competitive advantage of firms in industries [27, 28].

We analyzed the granted patent of the blockchain technology to study its recent development. We contributed to the existing literature by providing a profile of blockchain development by countries and companies. Understanding the current development trend is crucial for academic or practical researchers to plan their future research strategies.

A patent is an intellectual property that provides its owners a right to exclude others from the industrial utility of their invention for a certain period. A granted patent can only provide protection to the invention in the country where the patent was granted. The invention is not protected in countries where patent applicants did not seek protection. Thus, most international mobile phone companies apply for patents in some major countries.

\subsection{DATA SCOPE}

The United States is the largest economy in the world. Thus, most companies first apply for patents in the United States if their invention can be used in the global market. Moreover, most blockchain applications involve online transaction records. These online transactions can be performed without geographical boundaries. Companies must apply for patents to prevent others from imitating their inventions.

The Global Patent Search System (GPSS) provided by the Intellectual Property Office, Ministry of Economic Affairs, Taiwan, was used to search patents granted from the United States Patent and Trademark Office (USPTO). The granted patents in this database can be tracebacked to January 1976. However, most blockchain patents were granted in the 2010s. Because the term of U.S. patents is 20 years from the application filing of the patent, any blockchain patent filed before 1999 was no longer effective. Thus, we focused only on patents granted between January 2000 and December 2019. We analyzed the patent trend observed in all countries worldwide during these 20 years to realize the development of blockchain technology.

\subsection{KEYWORDS FOR DATABASE SEARCH}

We used the terms "block chain," "blockchain," and "chain of block" as keywords to search patents in the database. However, the term "block chain" is common in many other fields. For instance, the term "block chain" was used as a snow chain device for motor vehicle tires by Gun [29] or a metal chain used for moving (tow-away) automobiles by Hoffman [30]. Furthermore, in chemical industries, the term "block chain" is used for polymers (copolymers and homopolymers). Additionally, "block chain" is used in conveyor track chains. Thus, we analyzed all the patents to remove patents that were not related to information systems.

We used the International Patent Classification (IPC) 3 code to classify the acquired patents. The IPC code provided a hierarchical system for the classification of 
patents according to technology areas. The first hierarchy was employed to divide all the patents into eight categories: (A) human necessities, (B) operation performing and transporting, (C) chemistry metallurgy, (D) textiles and paper, (E) fixed construction, (F) mechanical engineering, lighting, heating, weapons, and blasting, $(\mathrm{G})$ physics, and (H) electricity. Blockchain used in information systems were discussed; it should belong to electricity, category $(\mathrm{H})$. Furthermore, the blockchain patent can be a part of a device. Thus, it could belong to physics, category $(\mathrm{G})$. Thus, only patents that were classified into physics and electricity were considered. We searched the patents granted between 2000 and 2019 and obtained 350 granted patents. Figure 1 presents the number of blockchain patents granted in the United States by year. Most patents (335) were granted between 2017 and 2019, which contributed to $95.7 \%$ of all blockchain patents. Only 15 patents (4.3\%) were granted between 2000 and 2016. Moreover, the topics of most blockchain patents applied in the 2000s were different from those of blockchain information systems. Thus, we studied the data obtained in the period range of 2017 to 2019.

The search commands used for the global patent search system (https://gpss.tipo.gov.tw/) were " $\left(\mathrm{IC}=\mathrm{G}^{*} \mathrm{OR} \mathrm{IC}=\mathrm{H}^{*}\right),(\mathrm{ID}=20170101: 20191231)$, and ((blockchain)@AB OR ( block chain )@AB OR (chain of block )@AB) NOT ((copolymers@AB), (homopolymers)@AB, or (polymers)@AB or (polyether)@AB or ) NOT ((conveyor track)@AB).”

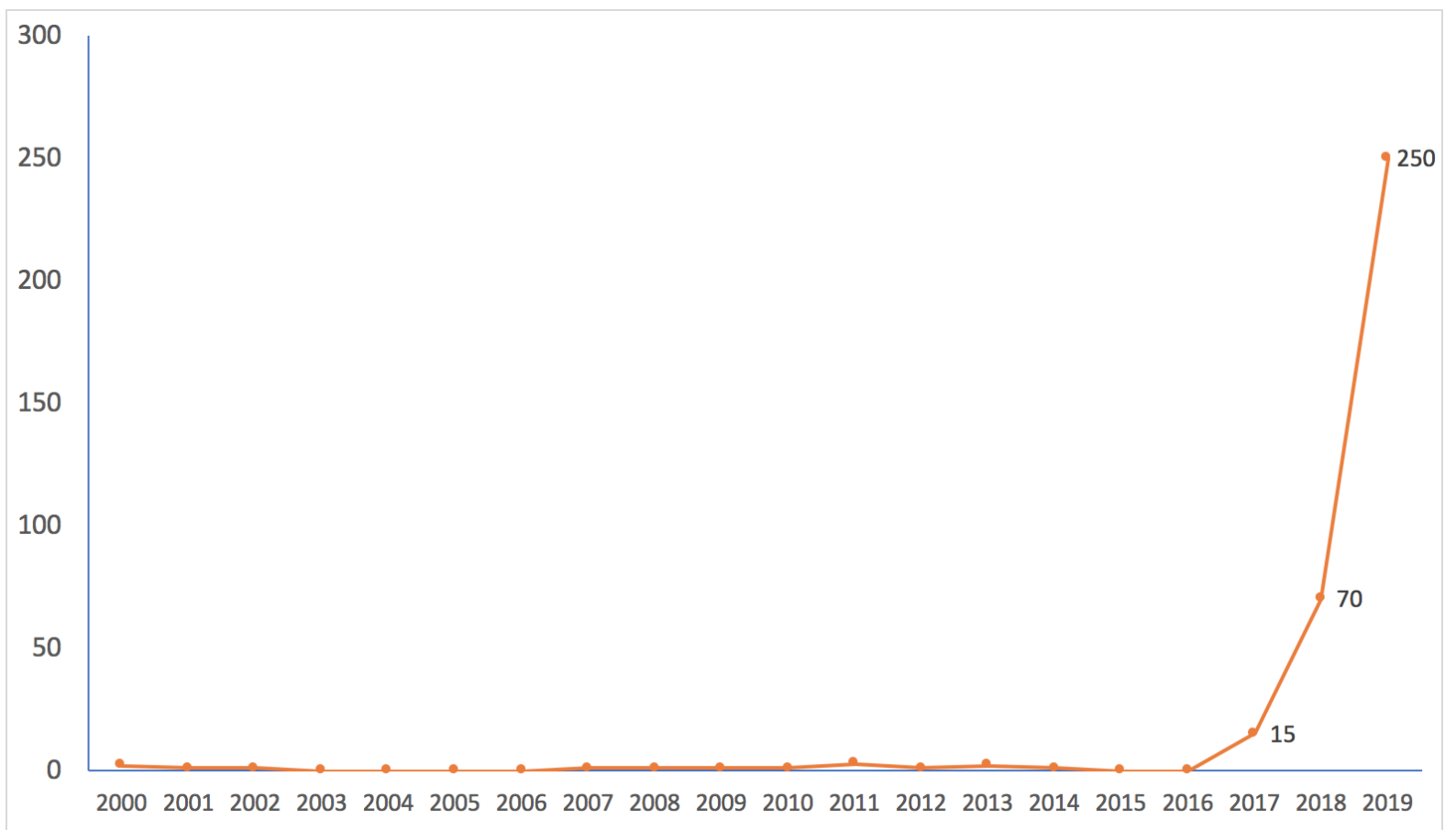

Figure 1. Blockchain patents by years.

\section{RESULTS of PATENT ANALYSIS}

\subsection{IPC Categories}


The analysis results revealed that the most blockchain patents belonged to IPC code H04L (transmission of digital information, e.g., telegraphic communication). A total of 282 patents belonged to this category, which contributed to $84.2 \%$. The second most patents were of G06F (Electric digital data processing), which contributed to 178 patents $(53.1 \%$ ), which was followed by G06Q (data processing systems or methods, specially adapted for administrative, commercial, financial, managerial, supervisory, or forecasting purposes) with 112 patents (33.4\%), and H04W (wireless communication networks) with 43 patents $(12.8 \%)$.

Table 1. Patents by IPC classification

\begin{tabular}{|c|c|c|c|}
\hline $\begin{array}{c}\text { IPC } \\
\text { Classification }\end{array}$ & Description & Count & Percent \\
\hline H04L & $\begin{array}{l}\text { transmission of digital information, e.g., } \\
\text { telegraphic communication }\end{array}$ & 282 & $84.2 \%$ \\
\hline G06F & electric digital data processing & 178 & $53.1 \%$ \\
\hline G06Q & $\begin{array}{l}\text { data processing systems or methods, specially } \\
\text { adapted for administrative, commercial, } \\
\text { financial, managerial, supervisory or } \\
\text { forecasting purposes; systems or methods } \\
\text { specially adapted for administrative, } \\
\text { commercial, financial, managerial, supervisory } \\
\text { or forecasting purposes }\end{array}$ & 112 & $33.4 \%$ \\
\hline H04W & wireless communication networks & 43 & $12.8 \%$ \\
\hline G06K & $\begin{array}{l}\text { recognition of data; presentation of data; record } \\
\text { carriers; handling record carriers }\end{array}$ & 19 & $5.7 \%$ \\
\hline $\mathrm{G} 16 \mathrm{H}$ & $\begin{array}{l}\text { healthcare informatics, i.e., information and } \\
\text { communication technology [ICT] specially } \\
\text { adapted for the handling or processing of } \\
\text { medical or healthcare data }\end{array}$ & 12 & $3.6 \%$ \\
\hline G06N & $\begin{array}{l}\text { computer systems based on specific } \\
\text { computational models }\end{array}$ & 11 & $3.3 \%$ \\
\hline G07C & $\begin{array}{l}\text { the time or attendance registers; registering or } \\
\text { indicating the working of machines; generating } \\
\text { random numbers; voting or lottery apparatus; } \\
\text { arrangements, systems or apparatus for } \\
\text { checking not provided for elsewhere }\end{array}$ & 10 & $3.0 \%$ \\
\hline $\mathrm{H} 04 \mathrm{~N}$ & pictorial communication, e.g., television & 10 & $3.0 \%$ \\
\hline
\end{tabular}

Note: Any patents can belong to more than one IPC classification.

\subsection{Countries}


More than half of U.S. patents of all categories were of foreign origin $(52.3 \%$ in 2018). However, three quarters $(253,75.5 \%)$ of blockchain patents were from the United States. Thus, the United States has the most awarded blockchain patents. Ireland has the second most awarded patents of $28(8.4 \%)$. Other countries contribute less than patents. Some patents were awarded to tax haven countries, such as the British Virgin Islands ( 8 patents, $2.4 \%$ ), Cayman Islands ( 3 patents, $0.9 \%$ ), and the Bahamas ( 1 patents, $0.3 \%$ ). The results indicated that the United States exhibits the most competence for blockchain technology.

Table 2. Patent by country

\begin{tabular}{|l|c|c|c|}
\hline Country & Country Code & Number of Patents & percentage \\
\hline United States & US & 253 & $75.5 \%$ \\
\hline Ireland & IE & 28 & $8.4 \%$ \\
\hline The British Virgin Islands & V.G. & 8 & $2.4 \%$ \\
\hline United Kingdom & G.B. & 6 & $1.8 \%$ \\
\hline Switzerland & CH & 5 & $1.5 \%$ \\
\hline China & C.N. & 5 & $1.5 \%$ \\
\hline Canada & CA & 4 & $1.2 \%$ \\
\hline Germany & DE & 4 & $1.2 \%$ \\
\hline Japan & J.P. & 4 & $1.2 \%$ \\
\hline Australia & A.U. & 3 & $0.9 \%$ \\
\hline South Korea & K.R. & 3 & $0.9 \%$ \\
\hline Cayman Islands & KY & 3 & $0.9 \%$ \\
\hline France & FR & 2 & $0.6 \%$ \\
\hline Sweden & SE & 2 & $0.6 \%$ \\
\hline Bahamas & BS & 1 & $0.3 \%$ \\
\hline Israel & IL & 1 & $0.3 \%$ \\
\hline India & IN & 1 & $0.3 \%$ \\
\hline Russia & R.U. & 1 & $0.3 \%$ \\
\hline Taiwan & T.W. & 1 & $0.3 \%$ \\
\hline
\end{tabular}

\subsection{Assignee}

In this study, the assignees (applicants) of blockchain patents were analyzed. We found that $36.4 \%$ patents were awarded to the top five companies, and IBM was in the first place that contributed the most blockchain patents (47 patents, $14.0 \%$ ), and Accenture Global Solution was in the second place with 28 patents $(8.4 \%)$, which was followed by Bank of America (24 patents, 7.2\%), Capital One Services (12 patents, $3.6 \%$ ), and Mastercard $(11,3.3 \%)$. Table 3 presents a list of companies with two or more blockchain patents.

\subsection{Term Frequency}

Term frequency (T.F.) is often used in the fields of text mining, natural language processing, and information retrieval to determine the frequency at which a term occurs 
in a document. Studies have used term frequency to analyze the patent document to establish the critical technology concept in grand patents [31, 32].

Moreover, in this study, term frequency was used to obtain the frequently used terms in a patent abstract. Table 4 presents the terms that have been used for more than 50 times in the abstracts of 335 patents. The frequently used terms were data, blocks, systems, transactions, networks, devices, information, chain, distributed ledger, hash, key, request, smart access, digital, receiving, nodes, identity, computers, value, record, private, entity, contract, messages, public, stored, cryptographic, and tokens.

A word cloud (tag cloud) can be used to visually represent the high-frequency terms used in text data. Typically, the word cloud is employed to depict the keyword metadata or tags of websites. Studies have used the word cloud to analyze patent documents $[33,34]$. We employed the word cloud to illustrate the frequently used terms in the abstract of blockchain patents (Figure 2).

In some cases, key terms were phrases rather than single words. N-gram can be used to determine new phrases that are not present in a predefined dictionary. In computational linguistics, $n$-gram is a contiguous sequence of $n$ items ( $n=1$ to infinity) obtained from the given text or speech sample. N-gram can be used as an extractor to automatically determine a critical phrase used in any patent [35]. We used 2-gram and 3 -gram to acquire the frequently used phrases in the abstracts of blockchain patents. Tables 5 and 6 present the results 2 -gram and 3-gram, respectively.

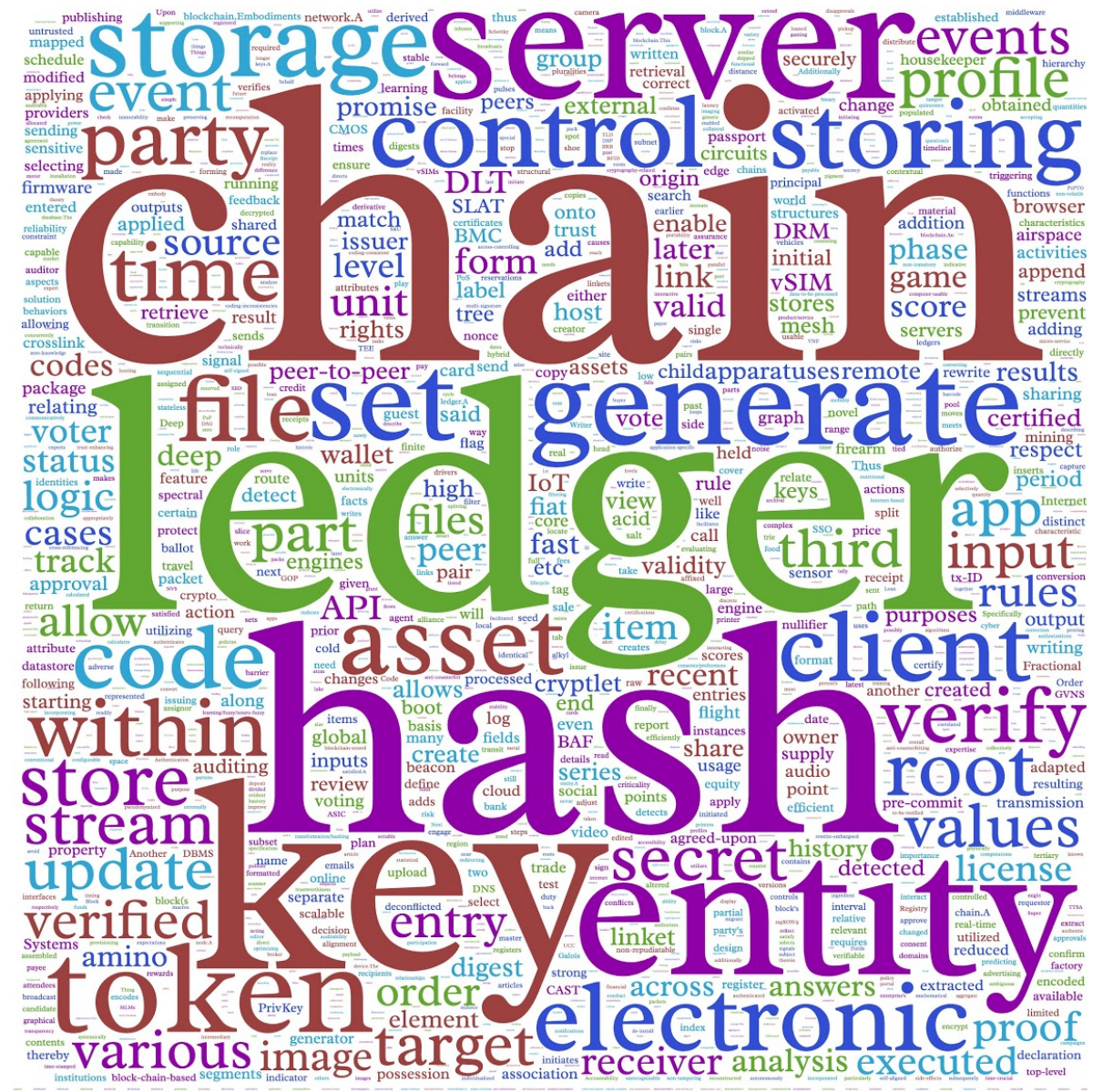

Created by https://www.wordclouds.com/

Figure 2. Word Cloud of Blockchain Patent Abstract 
Table 3. Patent by assignee

\begin{tabular}{|l|c|c|l|c|c|}
\hline Applicant (Assignee) & Patents & $\%$ & Applicant (Assignee) & Patents & $\%$ \\
\hline IBM & 47 & $14.0 \%$ & Wells Fargo Bank & 4 & $1.2 \%$ \\
\hline Accenture Global Solutions & 28 & $8.4 \%$ & Alibaba & 3 & $0.9 \%$ \\
\hline Bank of America & 24 & $7.2 \%$ & Dell & 3 & $0.9 \%$ \\
\hline Capital One Services & 12 & $3.6 \%$ & The Bank Of New York Mellon & 3 & $0.9 \%$ \\
\hline Mastercard & 11 & $3.3 \%$ & The Toronto-Dominion Bank & 3 & $0.9 \%$ \\
\hline Guardtime IP Holdings Limited & 8 & $2.4 \%$ & Verizon Patent And Licensing & 3 & $0.9 \%$ \\
\hline Madisetti Vijay K. & 8 & $2.4 \%$ & Winklevoss I.P. & 3 & $0.9 \%$ \\
\hline Black Gold Coin, Inc. & 7 & $2.1 \%$ & SAP & 2 & $0.6 \%$ \\
\hline Cisco & 7 & $2.1 \%$ & Sony & 2 & $0.6 \%$ \\
\hline Acronis International & 5 & $1.5 \%$ & Stampery & 2 & $0.6 \%$ \\
\hline Blockchain Asics & 5 & $1.5 \%$ & Uipco & 2 & $0.6 \%$ \\
\hline Tran Bao & 5 & $1.5 \%$ & Vmware & 2 & $0.6 \%$ \\
\hline Intel & 4 & $1.2 \%$ & Walmart Apollo & 2 & $0.6 \%$ \\
\hline Northern Trust & 4 & $1.2 \%$ & Wiig Rex & 2 & $0.6 \%$ \\
\hline Shocard & 4 & $1.2 \%$ & Xage Security & & \\
\hline
\end{tabular}

Table 4. Frequently used terms in blockchain patents

\begin{tabular}{|c|c|c|c|cc|}
\hline term & Frequency & term & Frequency & Term & Frequency \\
\hline data & 450 & key & 109 & Record & 84 \\
\hline block & 372 & request & 104 & Private & 81 \\
\hline systems & 260 & smart & 103 & Entity & 78 \\
\hline transaction & 239 & access & 102 & Contract & 75 \\
\hline network & 232 & digital & 99 & Message & 71 \\
\hline device & 198 & receiving & 97 & Public & 65 \\
\hline information & 166 & node & 94 & Stored & 65 \\
\hline chain & 158 & identity & 90 & Cryptographic & 64 \\
\hline distributed & 146 & computer & 88 & Token & 51 \\
\hline ledger & 134 & block & 86 & & \\
\hline hash & 134 & value & 86 & & \\
\hline
\end{tabular}

Table 5. Frequently used phrases (2-Gram)

\begin{tabular}{|l|l|l|l|l|l|}
\hline Phrase (2 Gram) & count & Phrase (2 Gram) & count & Phrase (2 Gram) & count \\
\hline smart-contract & 96 & block header & 21 & transaction record & 12 \\
\hline blockchain network & 73 & blockchain ledger & 20 & blockchain system & 11 \\
\hline distributed ledger & 65 & mobile service & 18 & committed tokens & 10 \\
\hline hash value & 42 & private blockchain & 18 & computer processors & 10 \\
\hline blockchain transaction & 35 & identity verification & 16 & control commands & 10 \\
\hline service provider & 34 & second blockchain & 16 & digital certificate & 10 \\
\hline distributed network & 27 & central service & 15 & digital identity & 10 \\
\hline computer program & 26 & transaction data & 15 & digital promise & 10 \\
\hline mobile device & 26 & blockchain database & 13 & identification information & 10 \\
\hline blockchain technology & 24 & transaction request & 13 & integrated circuit & 10 \\
\hline verification addresses & 24 & digital meeting & 12 & node device & 10 \\
\hline digital signature & 22 & operating procedure & 12 & target transaction & 10 \\
\hline
\end{tabular}


Table 6. Frequently used phrases (3-Gram)

\begin{tabular}{|c|c|}
\hline Phrase (3 Gram) & Count \\
\hline corresponding verification addresses & 12 \\
\hline private blockchain network & 22 \\
\hline multifactor personal identity & 12 \\
\hline personal identity verification & 12 \\
\hline first merged block & 11 \\
\hline
\end{tabular}

Created by http:/guidetodatamining.com/ngramAnalyzer/analyze.php

\section{DISCUSSION}

The results of the study revealed the development trend of blockchain technology. The rapid development of blockchain applications has received considerable attention from both information technology giants and startup companies. Patents are essential and indispensable to acquire technology competence and a sustainable competitive advantage of blockchain innovations. We analyzed the U.S. patents granted for blockchain and concluded that most U.S. patents were awarded to US-based companies. Half of the patents are of foreign origin. A total of three-quarters of U.S. patents of blockchain are of U.S. origin. Moreover, IBM is the major patentee with a contribution of approximately $14 \%$.

Blockchain can be used for any purpose of transaction data recording. Thus, blockchain is a high-potential technology. However, blockchain is still in the early stage of the technology life cycle. Industry practice should not consider only applications. Technical competence is the root of competitive advantage for future blockchain development. Blockchain innovations that are not based on a patented technology can be easily imitated, and the first-mover firm that develops an innovative application can obtain only a few competitive advantages because the second mover can easily imitate the application.

\section{AUTHOR BIOGRAPHIES}

Dr. Yann-Jy Yang is working as an Assistant Professor at the Department of Commerce Technology and Management, Chihlee University of Technology, Taiwan. Her current research interests include Intellectual Property Management, Entrepreneurship, and Innovation Management. Before joining Chihlee University of Technology, she worked as a researcher for Industrial Technology Research Institute (ITRI). She also had worked at MingDao University, Taiwan and National Tsing Hua University, Taiwan. She is also an inventor of several Taiwanese and U.S. patents.

Mr. Jiann-Chyau Hwang is now working at MetaEdge Cooperation, Taiwan as Vice President. Before joining MetaEdge, he worked for IBM Greater China Group as B2B \& Commerce solutions Leader.

\section{REFERENCES}

[1] S. Nakamoto. (2008). A Peer-to-Peer Electronic Cash System. Available: 
https://bitcoin.org/bitcoin.pdf

[2] G. Giudici, A. Milne, and D. Vinogradov, "Cryptocurrencies: Market Analysis and Perspectives," Journal of Industrial and Business Economics, vol. 47, no. 1, pp. 1-18, 2019. doi: 10.1007/s40812-019-00138-6

[3] Y. Yuan and F.-Y. Wang, "Blockchain and Cryptocurrencies: Model, Techniques, and Applications," IEEE Transactions on Systems, Man, and Cybernetics: Systems, vol. 48, no. 9, pp. 1421-1428, 2018. doi: 10.1109/tsmc.2018.2854904

[4] K. R. Lakhani and M. Iansiti, "The Truth About Blockchain," Harvard Business Review, vol. 95, pp. 118-127, 2017.

[5] H. Hou, "The Application of Blockchain Technology in E-Government in China," presented at the 2017 26th International Conference on Computer Communication and Networks (ICCCN), $2017 . \quad$ doi: 10.1109/iccen.2017.8038519

[6] D. Tse, B. Zhang, Y. Yang, C. Cheng, and H. Mu, "Blockchain Application in Food Supply Information Security," presented at the 2017 IEEE International Conference on Industrial Engineering and Engineering Management (IEEM), 2017. doi: 10.1109/ieem.2017.8290114

[7] A. Kamilaris, A. Fonts, and F. X. Prenafeta-Boldv́, "The Rise of Blockchain Technology in Agriculture and Food Supply Chains," Trends in Food Science \& Technology, vol. 91, pp. 640-652, 2019. doi: 10.1016/j.tifs.2019.07.034

[8] J. Wu and N. Tran, "Application of Blockchain Technology in Sustainable Energy Systems: An Overview," Sustainability, vol. 10, no. 9, 2018. doi: $10.3390 /$ su 10093067

[9] E. Erturk, D. Lopez, and W. Y. Yu, "Benefits and Risks of Using Blockchain in Smart Energy: A Literature Review," Contemporary Management Research, vol. 15, no. 3, pp. 205-225, 2019. doi: 10.7903/cmr.19650

[10] P. Mehrwald, T. Treffers, M. Titze, and I. Welpe, "Blockchain Technology Application in the Sharing Economy: A Proposed Model of Effects on Trust and Intermediation," presented at the Proceedings of the 52nd Hawaii International Conference on System Sciences, 2019. doi: 10.24251/hicss.2019.555

[11] M. Mettler, "Blockchain Technology in Healthcare: The Revolution Starts Here," presented at the 2016 IEEE 18th International Conference on e-Health Networking, Applications and Services (Healthcom), 2016. doi: 10.1109/HealthCom.2016.7749510

[12] S. Underwood, "Blockchain Beyond Bitcoin," Communications of the ACM, vol. 59, no. 11, pp. 15-17, 2016. doi: 10.1145/2994581

[13] B. Duan, Y. Zhong, and D. Liu, "Education Application of Blockchain Technology: Learning Outcome and Meta-Diploma," presented at the 2017 
IEEE 23rd International Conference on Parallel and Distributed Systems (ICPADS), 2017. doi: 10.1109/icpads.2017.00114

[14] H. Sun, X. Wang, and X. Wang, "Application of Blockchain Technology in Online Education," International Journal of Emerging Technologies in Learning (iJET), vol. 13, no. 10, 2018. doi: 10.3991/ijet.v13i10.9455

[15] K. Ito and M. O'Dair, "A Critical Examination of the Application of Blockchain Technology to Intellectual Property Management," in Business Transformation through Blockchain, 2019, pp. 317-335. doi: 10.1007/978-3-319-99058-3_12

[16] B. Wu and T. Duan, "The Advantages of Blockchain Technology in Commercial Bank Operation and Management," presented at the Proceedings of the 2019 4th International Conference on Machine Learning Technologies - ICMLT 2019, 2019. doi: 10.1145/3340997.3341009

[17] D. Patole, Y. Borse, J. Jain, and S. Maher, "Personal Identity on Blockchain," in Advances in Computing and Intelligent Systems(Algorithms for Intelligent Systems, 2020, pp. 439-446. doi: 10.1007/978-981-15-0222-4_41

[18] B. Notheisen, J. B. Cholewa, and A. P. Shanmugam, "Trading Real-World Assets on Blockchain," Business \& Information Systems Engineering, vol. 59, no. 6, pp. 425-440, 2017. doi: 10.1007/s12599-017-0499-8

[19] S. Saberi, M. Kouhizadeh, J. Sarkis, and L. Shen, "Blockchain Technology and Its Relationships to Sustainable Supply Chain Management," International Journal of Production Research, vol. 57, no. 7, pp. 2117-2135, 2018. doi: 10.1080/00207543.2018.1533261

[20] B. P. Abraham and S. D. Moitra, "Innovation Assessment through Patent Analysis," Technovation, vol. 21, no. 4, pp. 245-252, 2001. doi: 10.1016/s01664972(00)00040-7

[21] X. Li, Q. Xie, J. Jiang, Y. Zhou, L. Huang, and S. Change, "Identifying and Monitoring the Development Trends of Emerging Technologies Using Patent Analysis and Twitter Data Mining: The Case of Perovskite Solar Cell Technology," Technological Forecasting, vol. 146, pp. 687-705, 2019. doi: https://doi.org/10.1016/j.techfore.2018.06.004

[22] V. Albino, L. Ardito, R. M. Dangelico, and A. Messeni Petruzzelli, "Understanding the Development Trends of Low-Carbon Energy Technologies: A Patent Analysis," Applied Energy, vol. 135, pp. 836-854, 2014. doi: 10.1016/j.apenergy.2014.08.012

[23] P.-L. Chang, C.-C. Wu, and H.-J. Leu, "Using Patent Analyses to Monitor the Technological Trends in an Emerging Field of Technology: A Case of Carbon Nanotube Field Emission Display," Scientometrics, vol. 82, no. 1, pp. 5-19, 2009. doi: 10.1007/s11192-009-0033-y 
[24] C. V. Trappey, H.-Y. Wu, F. Taghaboni-Dutta, and A. J. C. Trappey, "Using Patent Data for Technology Forecasting: China Rfid Patent Analysis," Advanced Engineering Informatics, vol. 25, no. 1, pp. 53-64, 2011. doi: 10.1016/j.aei.2010.05.007

[25] T. U. Daim, G. Rueda, H. Martin, and P. Gerdsri, "Forecasting Emerging Technologies: Use of Bibliometrics and Patent Analysis," Technological Forecasting and Social Change, vol. 73, no. 8, pp. 981-1012, 2006. doi: 10.1016/j.techfore.2006.04.004

[26] L.-f. Yang, J.-h. Xu, and P. Neuhäusler, "Electric Vehicle Technology in China: An Exploratory Patent Analysis," World Patent Information, vol. 35, no. 4, pp. 305-312, 2013. doi: 10.1016/j.wpi.2013.06.002

[27] X. Yang, X. Yu, and X. Liu, "Obtaining a Sustainable Competitive Advantage from Patent Information: A Patent Analysis of the Graphene Industry," Sustainability, vol. 10, no. 12, 2018. doi: 10.3390/su10124800

[28] E. Pantano, C.-V. Priporas, S. Sorace, and G. Iazzolino, "Does InnovationOrientation Lead to Retail Industry Growth? Empirical Evidence from Patent Analysis," Journal of Retailing and Consumer Services, vol. 34, pp. 88-94, 2017. doi: 10.1016/j.jretconser.2016.10.001

[29] K. C. Gun, "Snow Chain Device for a Motor Vehicle Tire," ed: Google Patents, 1994.

[30] F. M. Hoffman, "Scotch Block Attachment Fitting," ed: Google Patents, 1984.

[31] H. Noh, Y. Jo, and S. Lee, "Keyword Selection and Processing Strategy for Applying Text Mining to Patent Analysis," Expert Systems with Applications, vol. 42, no. 9, pp. 4348-4360, 2015. doi: 10.1016/j.eswa.2015.01.050

[32] Y.-H. Tseng, C.-J. Lin, and Y.-I. Lin, "Text Mining Techniques for Patent Analysis," Information Processing \& Management, vol. 43, no. 5, pp. 12161247, 2007. doi: 10.1016/j.ipm.2006.11.011

[33] G. Halevi and H. F. Moed, "The Technological Impact of Library Science Research: A Patent Analysis," in Proceedings of 17th International Conference on Science and Technology Indicators, 2012, vol. 1, pp. 371-380.

[34] K.-Y. Kim and D.-G. Yang, "Group Decision Making for New Professor Selection Using Fuzzy Topsis," Journal of Digital Convergence, vol. 14, no. 9, pp. 229-239, 2016. doi: 10.14400/jdc.2016.14.9.229

[35] S. Sheremetyeva, "An Efficient Patent Keyword Extractor as Translation Resource," in Proceedings of the 3rd workshop on patent translation in conjunction with MT-Summit XII, Ottawa, 2009: Citeseer. 